\title{
Salt intake and eating habits of school-aged children
}

\author{
Yuko Ohta $^{1,2}$, Keiko Iwayama ${ }^{3}$, Hirotoshi Suzuki ${ }^{3}$, Satoko Sakata ${ }^{4}$, Shinichiro Hayashi ${ }^{2}$, Yoshio Iwashima ${ }^{2}$, \\ Akira Takata ${ }^{5}$ and Yuhei Kawano ${ }^{2,6}$
}

Salt restriction is important for the prevention and treatment of hypertension; however, salt consumption is still high in Japan. Improvements in dietary habits, including salt reduction in childhood, may contribute to the prevention of hypertension. The aim of the present study was to investigate the salt intake of school-aged children and the relationship between their diet diary and actual salt intake. The subjects comprised 580 schoolchildren (471 elementary school pupils and 109 junior high school pupils) who wanted to evaluate their salt intake in Kuji, a northeast coastal area in Japan. We estimated salt intake using spot urine samples and a formula. Lifestyle was assessed using a questionnaire. We also evaluated the salt intake and the lifestyles of 440 parents. The estimated salt intakes of elementary school pupils, junior high school pupils and their parents were $7.1 \pm 1.5$, $7.6 \pm 1.5$ and $8.0 \pm 1.7 \mathrm{~g}$ per day, respectively. The proportion of lower-grade children who achieved the recommended salt intake was low. In the multivariate analysis, the estimated salt intake of school-aged children correlated with their age, estimated salt intake of their parents and the menu priorities of the household. The estimated salt intake of the parents was associated with female gender, obesity, age and the habitual consumption of bread and noodles. In conclusion, the estimated salt intake of school-aged children positively correlated with the estimated salt intake of their parents, and the proportion of lower-grade children who achieved the recommended salt intake was low. Guidance on salt restriction for children and their parents may reduce the salt intake of school-aged children.

Hypertension Research (2016) 39, 812-817; doi:10.1038/hr.2016.73; published online 30 June 2016

Keywords: estimated salt intake; lifestyle; parents; school-aged children; spot urine samples

\section{INTRODUCTION}

Salt restriction is important for the prevention and treatment of hypertension. ${ }^{1}$ Although salt intake has gradually been decreasing in Japan, ${ }^{2}$ the proportion of those achieving the recommended salt intake is still low. High blood pressure (BP) is a major cause of cardiovascular disease in adults; however, its origins commonly begin in childhood. ${ }^{3,4}$ In children, excessive salt intake by overeating or consuming fast food has also been reported. 5,6

The mortality rate of strokes in adults was previously shown to be high, and there are many obese children in the Kuji area of northeastern Japan. ${ }^{7,8}$ If interventions to lower BP levels are initiated in children, then the development of high BP may be suppressed. Therefore, improvements in dietary habits, including salt reduction in childhood, are considered important for the prevention of hypertension. The aim of the present study was to investigate the salt intake of school-aged children and the relationship between the diet diary and actual salt intake in the Kuji area.

\section{SUBJECTS AND METHODS}

We obtained approval from the Board of Education and showed a document of the investigation contents to the parents of children who attended elementary and junior high schools managed by Kuji health center, a northeast coastal area in Iwate prefecture. The subjects comprised 580 schoolchildren (471 elementary school pupils and 109 junior high school pupils; 298 males and 282 females; average age $9.6 \pm 2.4$ years) who wanted to participate in this investigation. We estimated salt intake using spot urine samples and by asking their parents to fill out a questionnaire about their children's lifestyles regarding dietary habits (Table 1). We also evaluated the salt intake of 440 parents (138 males and 302 females; mean age $40.0 \pm 6.7$ years) and assessed their lifestyles using a selfadministered questionnaire.

We estimated 24-h salt excretion by measuring sodium $(\mathrm{Na})$ and creatinine (Cr) concentrations and by calculating it from a formula. This method is practiced at general medical facilities and is also the method for evaluating salt intake recommended by the Salt Reduction Committee of the Japanese Society of Hypertension. ${ }^{9}$ The reliability of the estimated 24-h salt excretion has been improved by incorporating estimated 24-h urinary $\mathrm{Cr}$ excretion based on age, height and body weight in the following formula: estimated salt intake $(\mathrm{g}$ per day $)=\{21.98 \times(\mathrm{Na}$ concentration in a spot urine sample $\left(\mathrm{mEq}^{-1}\right) / \mathrm{Cr}$ concentration in a spot urine sample $\left.\left(\mathrm{mEq}^{-1}\right)\right) \times(-2.04 \times$ age $+14.89 \times$ body $\quad$ weight $(\mathrm{kg})+16.14 \times$ height $\quad(\mathrm{cm})-2244.45)\}^{0.392} \times 0.0585$. We defined estimated 24-h urinary $\mathrm{Cr}$ excretion as $400 \mathrm{mg}$ per day (6-7 years old), $580 \mathrm{mg}$ per day (8-12 years old) and $1000 \mathrm{mg}$ per day (13 years old) according to the findings of a study that reported 24 -h urine collection from children. ${ }^{10}$

${ }^{1}$ Division of Internal Medicine, Kuroda Orthopedic Hospital, Fukuoka, Japan; ${ }^{2}$ Division of Hypertension and Nephrology, National Cerebral and Cardiovascular Center, Osaka, Japan; ${ }^{3}$ Health Center, Iwate, Japan; ${ }^{4}$ Department of Medicine and Clinical Science, Graduate School of Medical Sciences, Kyushu University, Fukuoka, Japan; ${ }^{5}$ Biobank, National Cerebral and Cardiovascular Center, Osaka, Japan and ${ }^{6}$ Department of Medical Technology, Teikyo University Fukuoka, Fukuoka, Japan Correspondence: Dr Y Ohta, Division of Internal Medicine, Kuroda Orthopedic Hospital, Jiromaru 5-7-9, Sawara-ku, Fukuoka 814-0165, Japan.

E-mail: y.ota@aroma.ocn.ne.jp

Received 28 January 2016; revised 28 April 2016; accepted 11 May 2016; published online 30 June 2016 
Table 1 Questionnaire about children's lifestyles regarding dietary habits

\begin{tabular}{|c|c|c|c|c|c|c|c|c|c|c|}
\hline \multirow{3}{*}{\multicolumn{2}{|c|}{ Breakfast }} & \multicolumn{3}{|c|}{ Frequency } & \multicolumn{2}{|c|}{ everyday } & sometimes & \multicolumn{3}{|c|}{ seldom } \\
\hline & & \multicolumn{3}{|c|}{ People who cook } & \multicolumn{2}{|l|}{ mother } & grandmother & \multicolumn{3}{|l|}{ others } \\
\hline & & \multicolumn{3}{|c|}{ Contents of meal } & \multicolumn{2}{|c|}{ Japanese } & Western & \multicolumn{3}{|l|}{ others } \\
\hline \multirow{3}{*}{\multicolumn{2}{|c|}{ Lunch }} & \multicolumn{3}{|c|}{ Frequency } & \multicolumn{2}{|c|}{ everyday } & sometimes & \multicolumn{3}{|c|}{ seldom } \\
\hline & & \multicolumn{3}{|c|}{ People who cook } & \multicolumn{2}{|l|}{ mother } & grandmother & \multicolumn{3}{|l|}{ others } \\
\hline & & \multicolumn{3}{|c|}{ Eating place } & \multicolumn{2}{|l|}{ home } & school & \multicolumn{3}{|l|}{ others } \\
\hline \multirow{3}{*}{\multicolumn{2}{|c|}{ Dinner }} & \multicolumn{3}{|c|}{ Frequency } & \multicolumn{2}{|c|}{ everyday } & sometimes & \multicolumn{3}{|c|}{ seldom } \\
\hline & & \multicolumn{3}{|c|}{ People who cook } & mother & gran & mother & others & & \\
\hline & & Eating & & & home & scho & & others & & \\
\hline Snacks & & Frequ & & & everyda & some & times & seldom & non & \\
\hline & & Kind & comm & ercia & lly avail & hand & nade & others & & \\
\hline & & Sweet & & twi & $e / d a y \leq$ & $1 /$ day & sometime & & non & \\
\hline Sweet drinks & & twice/ & & & $1 /$ day & some & times & none & & \\
\hline Vegetables & & twice/ & & & $1 /$ day & some & times & none & & \\
\hline Fruit & & twice/ & & & $1 /$ day & some & times & none & & \\
\hline Noodles & & twice/ & & & $1 /$ day & some & times & none & & \\
\hline Junk food & & twice/ & & & $1 /$ day & some & times & none & & \\
\hline Retort & & everyc & & & sometin & & none & & & \\
\hline Commercially av & ilable side d & lishes & twic & e/day & $1 / \mathrm{d}$ & some & times & none & & \\
\hline Eating out & & twice/ & & & $1 /$ day & some & times & none & & \\
\hline Seasoning of eati & g out & & taste & & & nilar & & bland taste & & \\
\hline Priority of menu & preference & nutri & 1 balan & & variety & cooking time & additive & househo & ld & others \\
\hline Seasoning of mea & & try bla & aste & & dislike & light tastes & ot particula & arly thinki & ing & \\
\hline
\end{tabular}

The protocol was explained in detail, and informed consent was obtained from each subject. This study was performed in accordance with institutional guidelines and approved by the Ethical Committee of the National Cerebral and Cardiovascular Center.

\section{Statistical analysis}

Values are presented as mean \pm s.d. Student's $t$-test and $\chi^{2}$ test were utilized where appropriate. The $P$-values of $<0.05$ were considered significant. All calculations were performed using a standard statistical package (JMP 10; SAS Institute, Cary, NC, USA).

\section{RESULTS}

As shown in Figure 1, the estimated salt intake of all school-aged children was widely distributed and average estimated salt intake was $7.2 \pm 1.5 \mathrm{~g}$ per day. The estimated salt intakes of male pupils and female pupils were $7.2 \pm 1.5$ and $7.1 \pm 1.4 \mathrm{~g}$ per day, respectively (Figure 2a). The estimated salt intake of junior high school pupils was higher than that of elementary school pupils $(7.6 \pm 1.5$ vs. $7.1 \pm 1.5 \mathrm{~g}$ per day, respectively; $P<0.01$; Figure $2 \mathrm{~b}$ ).

The target salt intake proposed by the Ministry of Health, Labour and Welfare in Japan is presented in Table $2 .{ }^{11}$ The estimated salt

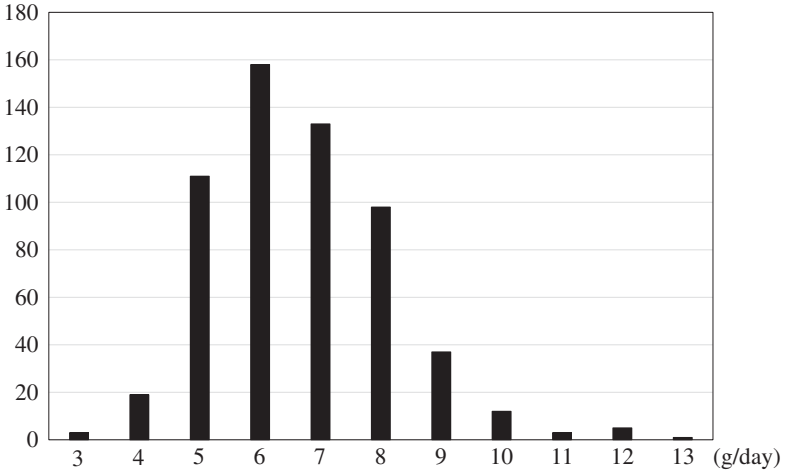

Figure 1 Estimated salt intake of all school-aged children $(N=580)$.

intakes of male pupils and female pupils in each age are shown in Figure 3. The proportion of lower-grade children who achieved the recommended salt intake was significantly lower than that of highergrade male children (37.7\% (6-7 years) vs. $76.7 \%$ (10-11 years) vs. $90.3 \%$ (over 12 years); $39.7 \%$ (8-9 years) vs. 76.7\% (10-11 years) vs. 
90.3\% (over 12 years), $P<0.01,76.7 \%$ (10-11 years) vs. $90.3 \%$ (over 12 years), $P<0.05)$ and female children $(37.5 \%$ (8-9 years) vs. $56.3 \%$ (10-11 years) vs. $55.1 \%$ (over 12 years), $P<0.05$ ). The proportion in
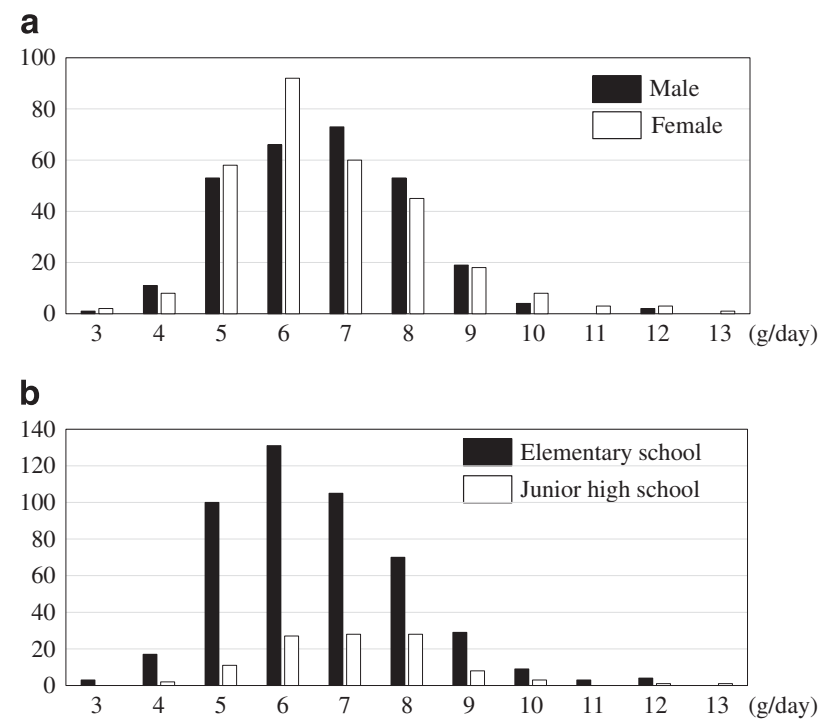

Figure 2 (a) Comparison of estimated salt intake between male and female pupils. (b) Comparison of estimated salt intake between elementary and junior high school pupils.

Table 2 Salt intake target ${ }^{9}$

\begin{tabular}{lcc}
\hline Salt intake criteria & Males & Females \\
\hline 12 Years old & $<9$ g per day & $<7.5$ g per day \\
$10-11$ Years old & $<8$ g per day & $<7.5$ g per day \\
$8-9$ Years old & $<7$ g per day & $<7$ g per day \\
$6-7$ Years old & $<6$ g per day & $<6$ g per day \\
$3-5$ Years old & $<5$ g per day & $<5$ g per day \\
$1-2$ Years old & $<4$ g per day & $<4$ g per day \\
\hline
\end{tabular}

male pupils was significantly higher than that in female pupils (10-11 years: $76.7 \%$ vs. $56.3 \%$, respectively; over 12 years: $90.3 \%$ vs. $55.1 \%$, respectively; all $P<0.01)$. On the other hand, the proportion of lowergrade children who achieved the recommendations from the US Dietary Reference Intakes of the Food and Nutrition Board of the Institute of Medicine ( $4-8$ years; $<4.85$ g per day, 9-13 years; $<5.61 \mathrm{~g}$ per day, 14 years; $<5.87$ g per day $)^{12}$ was low (6.6\% (4-8 years), $12.4 \%$ (9-13 years), $15.2 \%$ (14 years)) compared with that of highergrade children, as well as those who achieved the Japanese recommendations.

In the multivariate analysis, the estimated salt intake of the schoolaged children correlated with their age and the estimated salt intake of their parents (Table 3). Factors in the questionnaire that contributed to the estimated salt intake of school-aged children differed between elementary school pupils and junior high school pupils and between males and females (Table 4).

The average estimated salt intake of the children's parents was $8.0 \pm 1.7 \mathrm{~g}$ per day. The estimated salt intake of mothers was higher than that of fathers $(8.3 \pm 1.7$ vs. $7.4 \pm 1.6 \mathrm{~g}$ per day, respectively; $P<0.01)$. The estimated salt intakes of normotensive fathers, normotensive mothers and hypertensive parents are shown in Figure 4; the proportion of each group that achieved the recommended salt intake was $89.3 \%$ ( $<9 \mathrm{~g}$ per day), $31.8 \%(<7.5 \mathrm{~g}$ per day) and $8.9 \%(<6 \mathrm{~g}$ per day), respectively. However, the proportion of parents who achieved the World Health Organization (WHO) criteria $(<5 \mathrm{~g}$ per day $)^{13}$ was only $0.9 \%$. The estimated salt intake of parents negatively correlated with smoking and positively correlated with the female gender, body mass index, age and the habitual intake of bread and noodles (Table 5).

\section{DISCUSSION}

The present study showed that the proportion of lower-grade schoolaged children who achieved the recommended salt intake was low, and the estimated salt intake of children positively correlated with their age and the estimated salt intake of their parents.
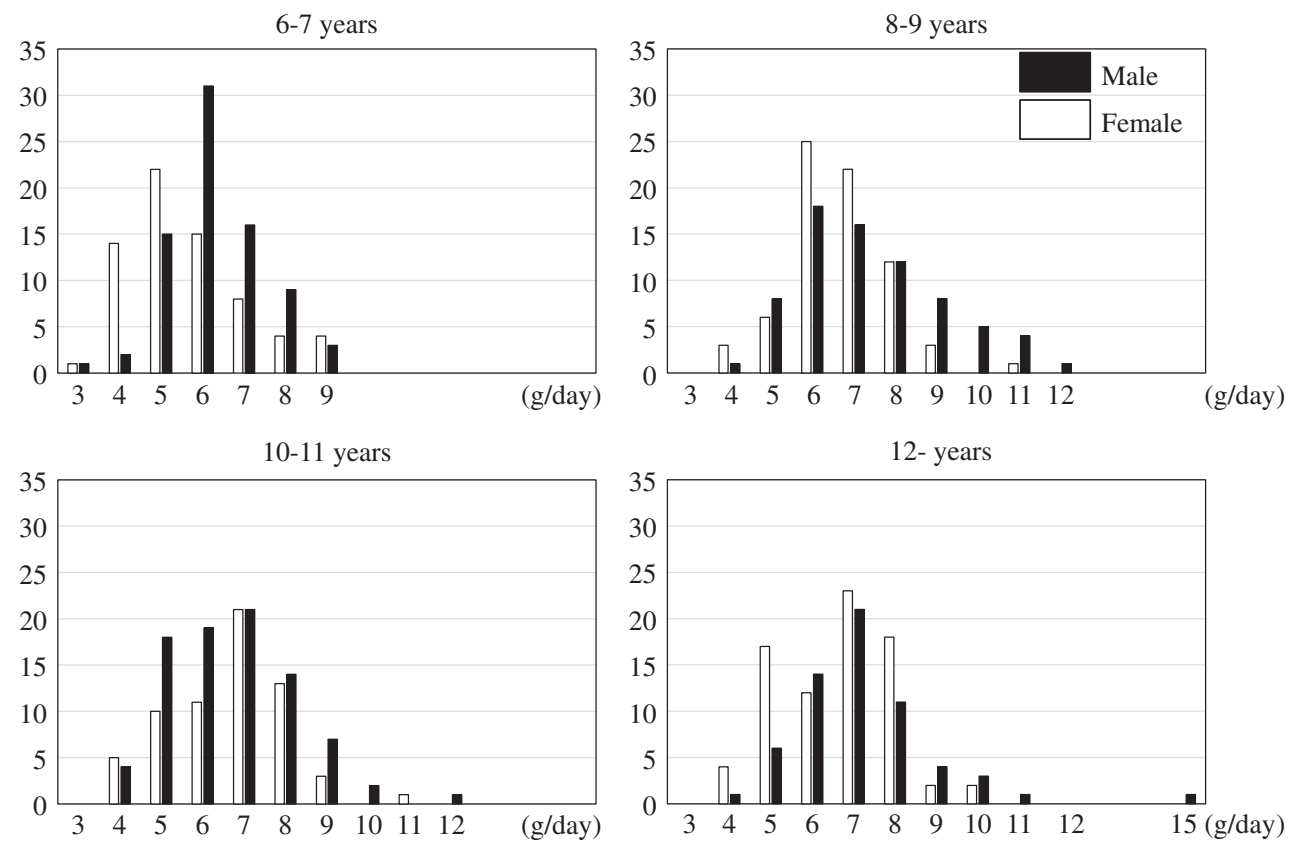

Figure 3 Estimated salt intake of school-aged children by age group. 
High salt intake is associated with obesity and high BP in children. ${ }^{14-16}$ The estimated salt intake of junior high school pupils was higher than that of elementary school pupils in the present study. This may be because of differences in overall energy expenditure and, thus, caloric intake, as our results showed that salt intake increased

Table 3 Clinical factors contributing to estimated salt intake of school-aged children: multivariate analysis

\begin{tabular}{lrr}
\hline & Partial r & P-value \\
\hline Estimated salt intake of parents & 0.190 & $<0.001$ \\
Age of school-aged children & 0.249 & $<0.001$ \\
Age of parents & -0.256 & 0.146 \\
\hline
\end{tabular}

Table 4 Questionnaire factors contributing to estimated salt intake of school-aged children: multivariate analysis

\begin{tabular}{llrr}
\hline Subjects & Factors & Partial r & P-value \\
\hline \multirow{2}{*}{ All } & Menu priorities of the household & 0.111 & 0.014 \\
Male & Snacks & -0.137 & 0.071 \\
& Snacks & -0.120 & 0.055 \\
Female & Dislike of light tastes & 0.170 & 0.054 \\
& Not specifically contemplating the & 0.142 & 0.028 \\
& Seasoning of meals & & \\
& Sweet drinks & -0.204 & 0.024 \\
& Breakfast & 0.253 & 0.019 \\
& Variety of food & -0.292 & 0.021 \\
& Balance of food nutrition & -0.318 & 0.044 \\
Elementary school & Menu priorities of the household & 0.122 & 0.014 \\
Junior high school & Commercially available side dishes & -0.290 & 0.007 \\
& Eating out (including commercially & 0.378 & 0.020 \\
& available lunch deliveries) & & \\
& Vegetables & 0.433 & 0.036 \\
\hline
\end{tabular}

a

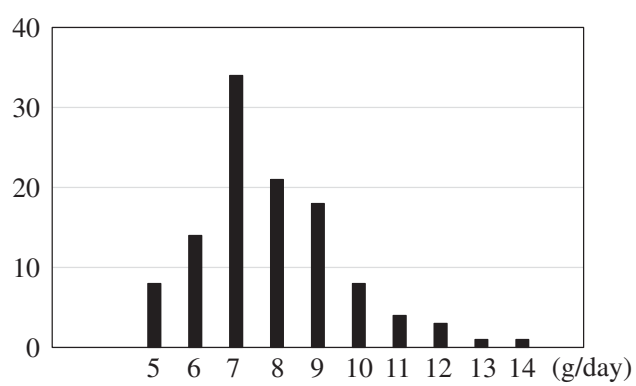

with age, agreeing with the findings of a study conducted in South London. ${ }^{10}$ In the present study, the estimated salt intake of schoolaged children exceeded the recommended amounts, similar to other Westernized societies, ${ }^{10,17,18}$ and the proportion of lower-grade children who achieved the recommended salt intake was low. The results were similar even for the US recommendations that are stricter than Japanese criteria. A previous study reported that salt intake was higher in children who had older siblings than first-born children; ${ }^{19}$ however, we did not assess the siblings of our subjects. In addition, the proportions of fathers and male pupils who achieved the recommended salt intake were high compared with their female counterparts. We had previously reported that the proportion of female adults in the same area who achieved the recommended salt intake was low compared with that of male adults. ${ }^{20}$ This may be because of a feature of that area and the low target value of females compared with males.

The estimated salt intake of all school-aged children correlated more strongly with the menu priorities of the household than with snacks in the present study. Salt intake was previously reported to be high in children who consumed more soft drinks or snacks. ${ }^{16,19,21}$ However, the estimated salt intake of female pupils was negatively associated with sweet drinks in the present study. An assessment of the eating frequency was included in our questionnaire; however, we

Table 5 Clinical and questionnaire factors contributing to estimated salt intake of parents: multivariate analysis

\begin{tabular}{lrr}
\hline & Partial r & P-value \\
\hline Females & 0.241 & $<0.001$ \\
Body mass index & 0.335 & $<0.001$ \\
Age & 0.364 & $<0.001$ \\
Smoking & -0.379 & 0.009 \\
Consciousness of salt restriction & 0.391 & 0.018 \\
Bread and noodles & 0.401 & 0.023 \\
\hline
\end{tabular}

\section{b}

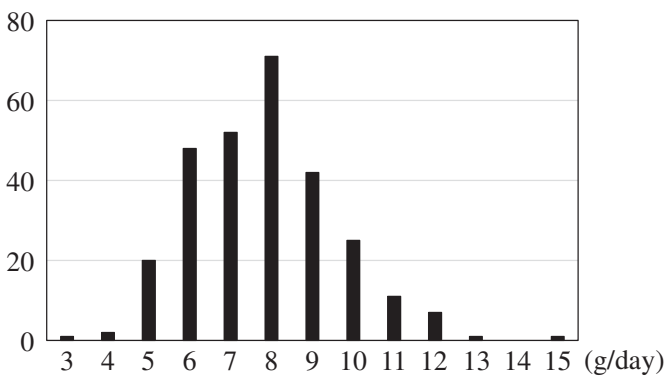

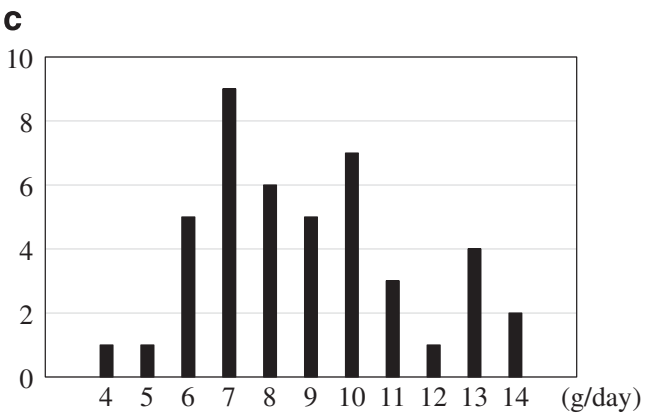

Figure 4 (a) Estimated salt intake of normotensive male parents. (b) Estimated salt intake of normotensive female parents. (c) Estimated salt intake of hypertensive parents. 
could not evaluate the details of dish types and amounts. The salt content of cooking at home might be higher than that commercially available, or the awareness of food intake might be low.

A high salt intake has been suggested to suppress salt taste receptors, ${ }^{22}$ and the salt intake of children has not been related to the child's own salty taste preference but to the salt intake behavior observed by their mother. ${ }^{23}$ Lifestyle changes in school-aged children through school-based interventions have been reported. ${ }^{24,25}$ In salt restriction education for children, the role of not only the school system but also their parents appeared to be important. In the present study, the estimated salt intake of school-aged children correlated with the estimated salt intake of their parents and the menu priorities of the household. Thus, parents need to restrict their own salt intake and change the menu priorities of the household in order to restrict salt intake by their children.

In the present study, the proportions of mothers and hypertensive parents who achieved the WHO and the Japanese recommended salt intakes were low. In addition, the estimated salt intake of parents was positively associated with body mass index, the habitual intake of bread and noodles and the consciousness of salt restriction and was negatively associated with smoking. We previously reported that patients with a metabolic syndrome had higher salt intakes, ${ }^{26}$ and body weight was a major determinant factor of salt intake. ${ }^{27}$ The effectiveness of salt reductions and weight loss in the treatment of hypertension was also confirmed by the TONE study. ${ }^{28}$ Thus, caloric restriction leads not only to reductions in body weight but also in salt intake and may contribute to improved BP control. The reason for the negative relationship between the salt intake of parents and smoking is unknown; however, the positive relationship between the salt intake of parents and the consciousness of salt restriction seems to indicate that the awareness of salt restriction may not lead to an actual reduction in salt intake, as reported previously. ${ }^{29}$

There were several limitations in this study. The subjects were not randomly recruited in this investigation, and the present investigation was conducted in Kuji, located in northeastern Japan. Therefore, the results obtained may not be representative of general school-aged children in Japan. Furthermore, we estimated salt intake by using spot urine samples. Spot urine sampling is inferior to 24-h urine collection in the assessment of salt intake. However, the reliability of spot urine methods has been improved using a formula that incorporated estimated 24-h urinary $\mathrm{Cr}$ excretion based on age, height and body weight. ${ }^{9}$ We defined estimated 24 -h urinary $\mathrm{Cr}$ excretion according to the findings of 24-h urine collection in children. ${ }^{10}$ In addition, urinary $\mathrm{Na}$ excretion and salt intake in children are known to show wide intraindividual and interindividual variations. ${ }^{14} \mathrm{~A}$ single urine collection may not be sufficient to accurately assess the salt intake of individuals. The final limitation is the lack of data on BP in the present study. Further studies are required to validate the estimated daily salt intakes and to elucidate the relationship between actual salt intake and $\mathrm{BP}$ in school-aged children.

In conclusion, the estimated salt intake of school-aged children positively correlated with the estimated salt intake of their parents, and the proportion of lower-grade children who achieved the recommended salt intake was low. Guidance on salt restriction for children and their parents may reduce the salt intake of school-aged children. A reduction in salt intake among children was previously reported to result in a decrease in BP. ${ }^{21,30}$ Therefore, salt reductions in schoolaged children will lessen the subsequent rise in BP with age and may reduce cardiovascular disease events in adulthood.

\section{CONFLICT OF INTEREST}

The authors declare no conflict of interest.

1 Shimamoto K, Ando K, Fujita T, Hasebe N, Higaki J, Horiuchi M, Imai Y, Imaizumi T, Ishimitsu $\mathrm{T}$, Ito $\mathrm{M}$, Ito $\mathrm{S}$, Itoh $\mathrm{H}$, Iwao $\mathrm{H}$, Kai H, Kario K, Kashihara N, Kawano $\mathrm{Y}$, Kim-Mitsuyama S, Kimura G, Kohara K, Komuro I, Kumagai H, Matsuura H, Miura K, Morishita R, Naruse M, Node K, Ohya Y, Rakugi H, Saito I, Saitoh S, Shimada K, Shimosawa T, Suzuki H, Tamura K, Tanahashi N, Tsuchihashi T, Uchiyama M, Ueda S, Umemura S, Japanese Society of Hypertension Committee for Guidelines for the Management of Hypertension. The Japanese Society of Hypertension guidelines for the management of hypertension (JSH 2014). Hypertens Res 2014; 37: 286-290.

2 Life-Style Related Diseases Control General Affairs Division, Health Service Bureau, Ministry of Health, Labour and Welfare. National Health and Nutrition Survey Japan 2013, Ministry of Health, Health, Labour and Welfare, 2013 (in Japanese).

3 Li S, Chen W, Srinivasan SR, Berenson GS. Childhood blood pressure as a predictor of arterial stiffness in young adult: the Bogalusa Heart Study. Hypertension 2004; 43: 541-546.

4 Franks PW, Hanson RL, Knowler WC, Sievers ML, Bennett PH, Looker HC. Childhood obesity, other cardiovascular risk factors, and premature death. N Engl J Med 2010; 362: 485-493.

5 Kar S, Khandelwal B. Fast foods and physical inactivity are risk factors for obesity and hypertension among adolescent school children in east district of Sikkim, India. J Nat Sci Biol Med 2015; 6: 356-359.

6 Meneton P, Lafay L, Tard A, Dufour A, Ireland J, Ménard J, Volatier JL. Dietary sources and correlates of sodium and potassium intakes in the French general population. Eur $\mathrm{J}$ Clin Nutr 2009; 63: 1169-1175.

7 Ministry of Health, Labour and Welfare. http://www.mhlw.go.jp/toukei/saikin/hw/jinkou/ other/losibou.

8 Ministry of Education, Culture, Sports, Science and Technology. http://www.pref.iwate. jp/webdb/view/outside/s14Tokei/bnyaBtKekka.html?C=B1801\&R=I005.

9 Tsuchihashi T, Kai H, Kusaka M, Kawamura M, Matsuura H, Miura K, Ando K, Maruyama S, Hayabuchi H, Takagi Y, Nakahigashi N, Sato T, Kawano Y. Report of the Salt Reduction Committee of the Japanese Society of Hypertension: (3) Assessment and application of salt intake in the management of hypertension. Hypertens Res 2013; 36: 1026-1031.

10 Marrero NM, He FJ, Whincup P, Macgregor GA. Salt intake of children and adolescents in South London: consumption levels and dietary sources. Hypertension 2014; 63: 1026-1032.

11 Ministry of Health, Labour and Welfare. Dietary reference intakes for Japanese, 2010. Department of Health, Ministry of Health, Labour and Welfare: Tokyo, 2009 (in Japanese).

12 United States Department of Agriculture National Agricultural Library. Dietary Reference Intakes: Electrolytes and Water. https://fnic.nal.usda.gov/sites/fnic.nal.usda.gov/ files/uploads/electrolytes water.pdf.

13 WHO. Guideline: Sodium intake for adults and children. World Health Organization (WHO): Geneva, 2012.

14 Hanevold CD. Sodium intake and blood pressure in children. Curr Hypertens Rep 2013; 15: 417-425.

15 Woodruff SJ, Fryer K, Campbell T, Cole M. Association among blood pressure, salt consumption and body weight status of students from south-western Ontario. Public Health Nutr 2014; 17: 1114-1119.

16 Grims CA, Wright JD, Liu K, Nowson CA, Loria CM. Dietary sodium intake is associated with total fluid and sugar-sweetened beverage consumption in US children and adolescents aged 2-18y: NHANES 2005-2008. Am J Clin Nutr 2013; 98: 189-196.

17 Cotter J, Cotter MJ, Oliveira P, Cunnha P, Polónia J. Salt intake in children 10-12 years old and its modification by active working practices in a school garden. $J$ Hypertens 2013; 31: 1966-1971.

18 Brown IJ, Tzoulaki I, Candeias V, Elliott P. Salt intakes around the world: implications for public health. Int J Epidemiol 2009; 38: 791-813.

19 Morinaga Y, Tsuchihashi T, Ohta Y, Matsumura K. Salt intake in 3-year-old Japanese children. Hypertens Res 2011; 34: 836-839.

20 Ohta Y, Nakamura K, Ohgami Y, Iwaki K, Hayashi S, Iwashima Y, Kishida M, Yoshihara F, Nakamura S, Takata A, Kawano Y. Salt intake and consciousness of salt restriction in one local residents in Iwate prefecture: one-year follow-up study. Ketsuatsu 2015; 22: 67-72.

21 He FJ, Marrero NM, MacGregor GA. Salt intake is related to soft drink consumption in children and adolescents: a link to obesity? Hypertension 2008; 51: 629-634.

22 He FJ, MacGregor GA. Importance of salt in determining blood pressure in children: meta-analysis of controlled trials. Hypertension 2006; 48: 861-869.

23 Mastsuzaki H, Muto T, Haruyama Y. School children's salt intake is correlated with salty taste preference assessed by their mothers. Tohoku J Exp Med 2008; 215: 71-77.

24 Bacardí-Gascon M, Pérez-Morales ME, Jiménez-Cruz A. A six month randomized school intervention and an 18-month follow-up intervention to prevent childhood obesity in Mexican elementary schools. Nutr Hosp 2012; 27: 755-762.

25 He FJ, Wu Y, Feng XX, Ma J, Ma Y, Wang H, Zhang J, Yuan J, Lin CP, Nowson C, MacGregor GA. School based education programme to reduce salt intake in children 
and their families (School-EduSalt): cluster randomized controlled trial. BMJ 2015; 350: h770.

26 Ohta Y, Tsuchihashi T, Arakawa K, Onaka U, Ueno M. Prevalence and lifestyle characteristics of hypertensive patients with metabolic syndrome followed at an outpatient clinic in Fukuoka, Japan. Hypertens Res 2007; 30: 1077-1082.

27 Ohta Y, TsuchihashiT, Miyata E, Onaka U. Usefulness of self-monitoring of urinary salt excretion in hypertensive patients. Cin Exp Hypertens 2009; 31: 690-697.

28 Whelton PK, Appel LJ, Espeland MA, Applegate WB, Ettinger WH, Kostis JB, Kumanyika S, Lacy CR, Johnson KC, Folmar S, Cutler JA. Sodium reduction and weight loss in the treatment of hypertension in older persons. A randomized controlled trial of nonpharmacologic interventions in the elderly (TONE). TONE Collaborative Research Group. JAMA 1998; 279: 839-846.

29 Ohta Y, Tsuchihashi T, Ueno M, Kajioka T, Onaka U, Tominaga M, Eto K. Relationship between the awareness of salt restriction and the actual salt intake in hypertensive patients. Hypertens Res 2004; 27: 243-246.

30 Geleeijnse JM, Hofman A, Witteman JC, Hazebroek AA, Valkenburg HA, Grobbee DE. Long-term effects of neonatal sodium restriction on blood pressure. Hypertension 1997; 29: 913-917. 